\title{
200-kg large explosive detonation facing 50-km thick crust beneath west Qinling, northeastern Tibetan plateau*
}

\author{
Qiusheng $\mathrm{Li}^{1,2, \uparrow} \quad$ Rui Gao $^{1,2} \quad$ Haiyan Wang ${ }^{1,2} \quad$ Jisheng Zhang ${ }^{1,2}$ \\ Zhanwu Lu ${ }^{1,2}$ Pengwu Li ${ }^{1,2}$ Ye Guan ${ }^{1,2}$ and Rizheng He ${ }^{1,2}$ \\ ${ }^{1}$ Lithosphere Research Centre, Institute of Geology, Chinese Academy of Geological Sciences, Beijing 100037, China \\ ${ }^{2}$ Eearthprobe and Geodynamics Open Laboratory of Chinese Academy of Geological Sciences, Beijing 100037, China
}

\begin{abstract}
It is difficult to acquire deep seismic reflection profiles on land using the standard oil-industry acquisition parameters. This is especially true over much of Tibetan plateau not only because of severe topography and rapid variation of both velocity and thickness of near-surface layer, but also strong attenuation of seismic wave through the thickest crust of the Earth. Large explosive sources had been successfully detonated in US, but its application in Tibetan plateau rarely has an example of good quality. Presented herein is the data of a $200-\mathrm{kg}$ single shot we recorded in west Qinling, northeastern Tibetan plateau. The shot gather data with phenomenal signal-to-noise ratios illustrate the energy of the PmP phase. Although the observations are only limited to the northeastern Tibetan plateau and thus cannot comprise an exhaustive study, they nevertheless suggest that large explosions may be a useful exploration tool in Tibetan Plateau where standard seismic sources and profiling methods fail to produce adequate data of low crust.
\end{abstract}

Key words: northeastern Tibetan plateau; deep seismic reflection profile; Moho, large explosive sources CLC number: P315.8 Document code: A

\section{Introduction}

Over the last 30 years, the application of seismic reflection profiling method to the study of lower crust has proved highly successful (Brown, 1987; Brown et al, 1987). Land seismic profiling is considerably more difficult and time-consuming to acquire seismic data than at sea, hence the costs of onshore acquisition are prohibitively high. In addition, land seismic data are usually poorer in quality than marine seismic data because of the adverse effects of variable near-surface conditions, less efficient seismic source coupling, increased environmental noise, and irregular acquisition geometry.

As a seismic source, large explosive sources have been utilized almost exclusively for wide-angle seismic reflection and refraction studies of the Earth's crust and upper mantle. The objective of wide-angle seismic re-

\footnotetext{
* Received 7 April 2009; accepted in revised form 15 June 2009; published 10 August 2009.

* Corresponding author. e-mail: liqiusheng@cags.ac.cn, lqs1958@163.com
}

flection and refraction profiling permits the explosive source wave field to be coarsely sampled in time and space, which is just required by limited funding. This coarse, low-resolution sampling has led to the widely held notion that the source itself has poor resolving capabilities. Only when these same sources had been recorded with digital instrumentation and densely spaced receiver arrays in the late $1980 \mathrm{~s}$, has it been possible to show that this earlier notion is erroneous.

The first hints of true resolving power of large explosive sources came when seismologists began to use instrumentation with standard industry reflection spreads. This has allowed the explosive source wave field to be recorded using tight group spacing and large-dynamic-range, high-frequency-response instrumentation. Five reflection spreads were used to record the large explosions detonated during a seismic refraction study across northwestern Nevada (Jarchow et al, 1990). To surprise, the images of the crust and upper mantle obtained in this effort had a broad frequency bandwidth and were not severely contaminated by 
source-generated noise. Once again, the clear, high-resolution images of the crust and upper mantle were obtained by "piggyback" recording effort during a USGS seismic refraction study in west-central Arizona (Mooney and Brocher, 1987). In the data from the profile, conducted in south-central Washington on the Columbia River Basalt Plateau, as before, clear seismic images were obtained, which is especially remarkable in this area that has long been considered "seismically inaccessible."

Slightly later, the "piggyback" recording effort had been used by the INDEPTH group to probe how deformation was going on beneath Himalayas and southern Tibetan plateau (Zhao et al, 1993, 1997). The stack section detailed the geometry of the Main Himalayan Thrust (MHT), under which the Indian continental crust was subducting beneath the deforming leading edge of Eurasia, and presented a Moho depth of 72-75 km. However, significant controversy remains because the explosions detonated during their INDEPTH I and II programs have scarcely provided field shot gather with adequate signal-to-noise ratios for delineating the features in the topmost upper mantle to the north of the Indus-Yarlung Tsanpo suture.

This article presents a typical example of large explosive application in the northeastern Tibetan plateau. The data discussed here are from a program conducted during the years of 2004 to 2007 that is expected to image the crust of the West Qinling orogen. As a consequence, it suggests that the problem of insufficient source power encountered periodically during the land seismic data acquisition could be partly resolved by large explosive shooting in deep drill hole in the areas with high ambient noise levels or signal-penetration impediment by near-surface velocity structure (e.g. Tibetan plateau).

\section{Acquisitions}

The seismic profiling experiment field is located at the northeastern margin of Tibetan plateau (Figure 1), where is the junction domain of North and South China continents. The primary objectives of the experiment are: (1) to provide a high-quality reflection image of the Moho boundary across the entire orogen; (2) to evaluate crustal signatures and to search mantle structure (remnants of Mesozoic subduction?) beneath the orogen; and (3) to explore the ways for solving the problem of "seismically inaccessible". The field has long been consid- ered "seismically inaccessible" using the standard oil-industry acquisition parameters because of complex surface condition and subsurface structure.

Experimental design was integrated with explosive acquisition (480 channels, 50-m station spacing in an $24 \mathrm{~km}$ active spread; SN388 System 2 recording system) (Table 1) with $20,40 \mathrm{~kg}$ shots fired in the $28-\mathrm{m}$ deep holes every $100 \mathrm{~m}$ and $400 \mathrm{~m}$, and $200 \mathrm{~kg}$ shots every $5 \mathrm{~km}$ (Table 2). Shots were repeated twice at each shot-point at either end of the advancing spread (resulting in an effective split spread, nominal fold of 120), and were recorded to $30 \mathrm{~s}$ at a $2 \mathrm{~ms}$ sample rate. The acquisition proceeded from the north to the south to take

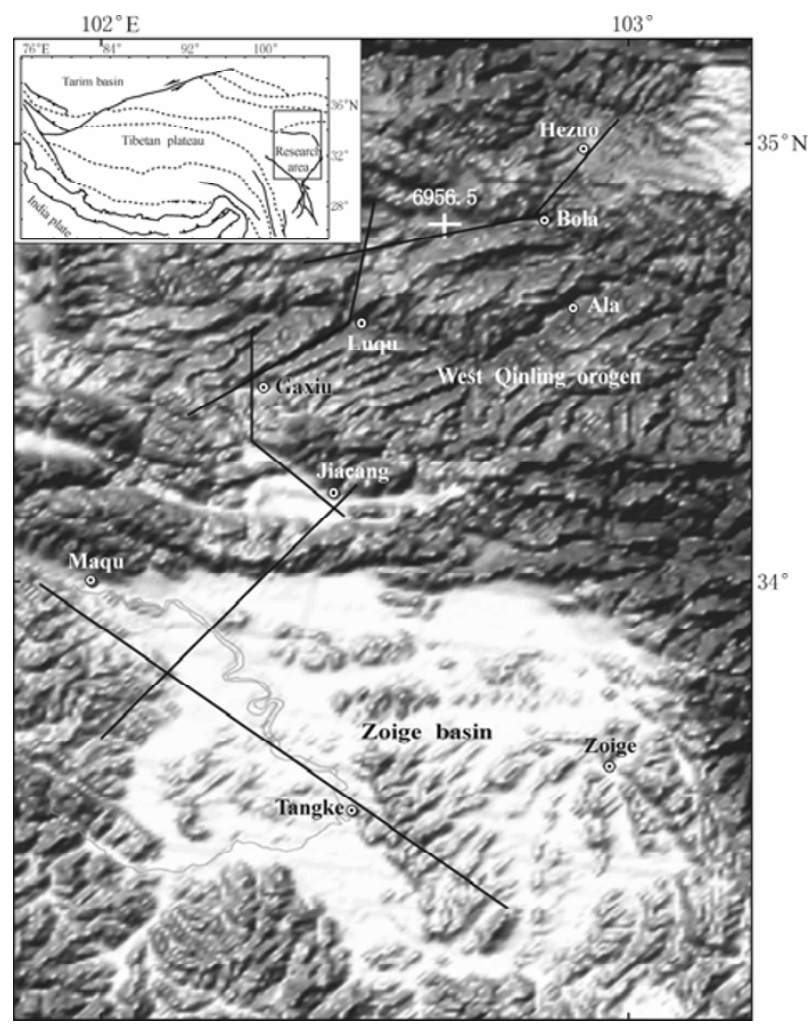

Figure 1 Schematic map of seismic line through northeastern Tibetan plateau (the box within the inset) (from Wang et al, 2007).

Table 1 Acquisition parameters for improved standard oil-industry

\begin{tabular}{ll||ll}
\hline Shot interval & $\begin{array}{l}400 \mathrm{~m} \text { nominal } \\
\text { for normal shot } \\
\text { Dynamite }\end{array}$ & Far offset $/ \mathrm{m}$ & 12125 \\
Source & $\begin{array}{l}\text { Spread } \\
\text { Charge size }\end{array}$ & $\begin{array}{l}\text { symmetric } \\
\text { split }\end{array}$ \\
& for nominal & Sample rate $/ \mathrm{ms}$ & 2 \\
Shot depth $/ \mathrm{m}$ & $28 \times 2$ & Record length $/ \mathrm{s}$ & 30 \\
Nominal fold & 30 & Low-cut filter $/ \mathrm{Hz}$ & 15 \\
Geophone type & $20 \mathrm{DX}-10 \mathrm{~Hz}$ & High-cut filter $/ \mathrm{Hz}$ & 250 \\
Group interval/m & 50 & Notch filters & out \\
Near offset $/ \mathrm{m}$ & 175 & & \\
\hline
\end{tabular}


the best advantage of weather and cultural considerations, and was coordinated so as to minimize noise conditions without delaying roll-along of the shots.

The quality of the shots was generally excellent with signal returns above ambient noise typically in excess of $20 \mathrm{~s}$ TWT. The preliminary results indicate a highly reflective lower crust (Figure 2), particularly in West Qinling, a Moho signature characterized by a sharp increase band in reflectivity at the base of the crust, and a typical shot gather as Figure 3 .

Table 2 Acquisition parameters for large explosive shooting

\begin{tabular}{ll||ll}
\hline Shot interval & $\begin{array}{l}5000 \mathrm{~m} \text { for } \\
\text { additional shot } \\
\text { Dynamite }\end{array}$ & Far offset $/ \mathrm{m}$ & 12125 \\
Source & $\begin{array}{l}\text { Spread } \\
\text { Charge size }\end{array}$ & $\begin{array}{l}\text { symmetric } \\
\text { split }\end{array}$ \\
& $\begin{array}{l}\text { additional shot } \\
\text { Sample rate } / \mathrm{ms}\end{array}$ & 2 \\
Shot depth $/ \mathrm{m}$ & $50 \times 3$ & Record length $/ \mathrm{s}$ & 30 \\
Geophone type & $20 \mathrm{DX}-10 \mathrm{~Hz}$ & Low-cut filter $/ \mathrm{Hz}$ & 15 \\
Group interval $/ \mathrm{m}$ & 50 & High-cut filter $/ \mathrm{Hz}$ & 250 \\
Near offset $/ \mathrm{m}$ & $175 \mathrm{~m}$ & & \\
\hline
\end{tabular}

As expected, our experiment results demonstrate the multifold is not always requisite because the data from single 200-kg explosions detonated with adequate signal-to-noise ratios for delineating the features of upper mantle enough. For example, the shot gathers we recorded in the shotpoint No.6956.5 (the location is marked with a white cross in Figure 1) have a high signal-to-noise ratio at the two-way travel times of 16.5-17 s. Our observation data dependably exemplify the frequency bandwidth attainable from large explosions in the Tibetan plateau. On the raw shot gathers, the seismic energy returning from the upper crust is composed of frequencies as high as $90 \mathrm{~Hz}$ and the energy from the Moho is composed of frequencies up to $40 \mathrm{~Hz}$ (Figure 4). Although their relative amplitudes are not high, these high-frequency components have a good signal-to-noise ratio and, as a consequence, can be boosted using the well-known techniques such as spiking deconvolution. This suggests that large explosions, despite their low dominant frequencies, may actually have a broader recoverable frequency bandwidth than the standard, less powerful sources.

The significance of our observation perhaps lies in giving an actual example again to contradict a firmly entrenched rule that high-frequency seismic energy (hence seismic resolution) decreases with increasing shot size.

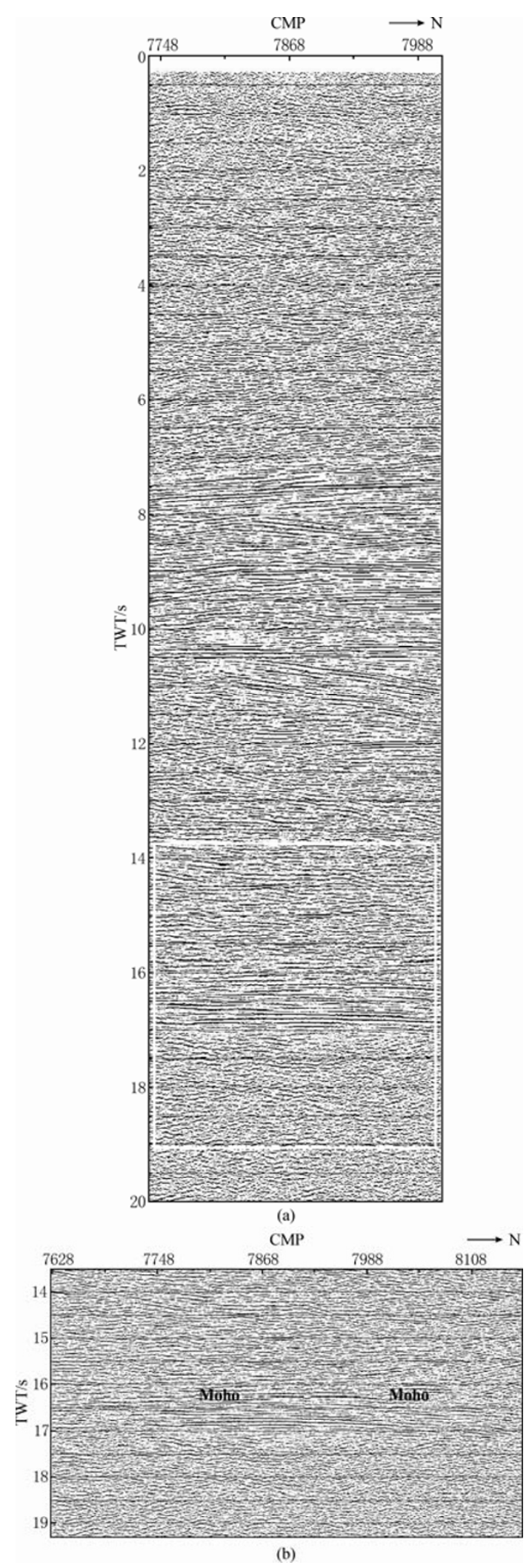

Figure 2 Seismic reflection signature of west Qinling orogen. (a) Whole crust; (b) Around Moho discontinuity [partial enlargement of (a)]. 


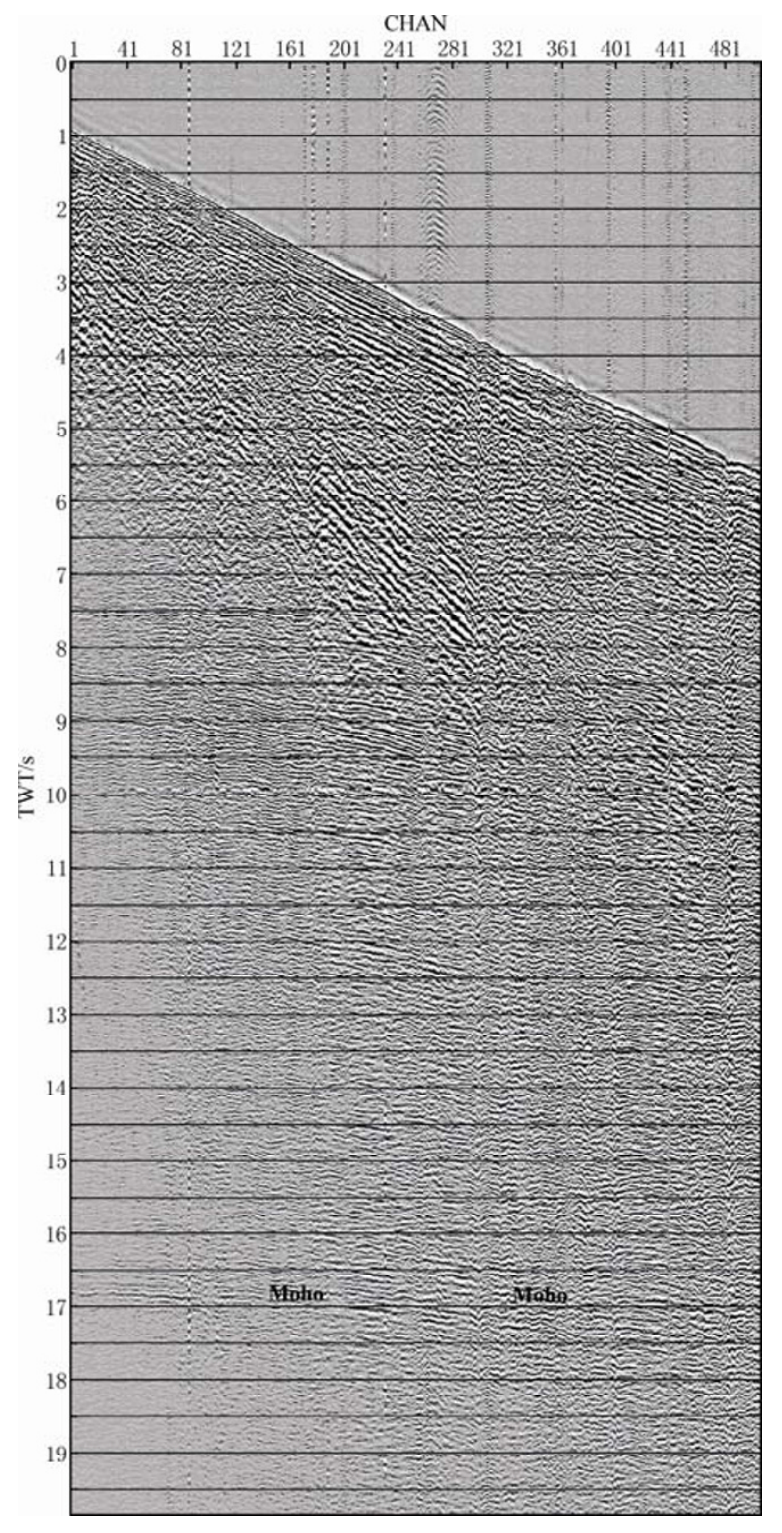

Figure 3 A typical shot gather recorded by improving industry reflection spreads deployed during our northeastern Tibetan plateau seismic program. The Moho (base of the crust) corresponds to a sharp increase band at the 16.5-17 s two-way time. The recording parameters used for this gather shown as Table 2.

The geological significance for the reflectivity of Moho has been translated in other publications (Zhang et al, 2004; Gao et al, 2006a, b; Wang et al, 2007) as indicated by the presence of clear multi-phase bands of gentle extension beneath the more reflective lower crust, traceable for the distances of more than $200 \mathrm{~km}$ from North to South beneath the Qinling orogen observed between 16.8 and $18.2 \mathrm{~s}$ TWT. Even the conservative velocity estimates would place these features at the depths of $51.0-54.6 \mathrm{~km}$ evaluated at a velocity of
$6.0 \mathrm{~km} / \mathrm{s}$ (Li et al, 2004; Wang et al, 2003a, b; Zhao et al, 2005; Zhang et al, 2008). These reflections have marked some of the clearest observations ever conducted in the Tibetan plateau with the seismic reflection technique and the viability of seismic reflection method in imaging continental lithosphere.

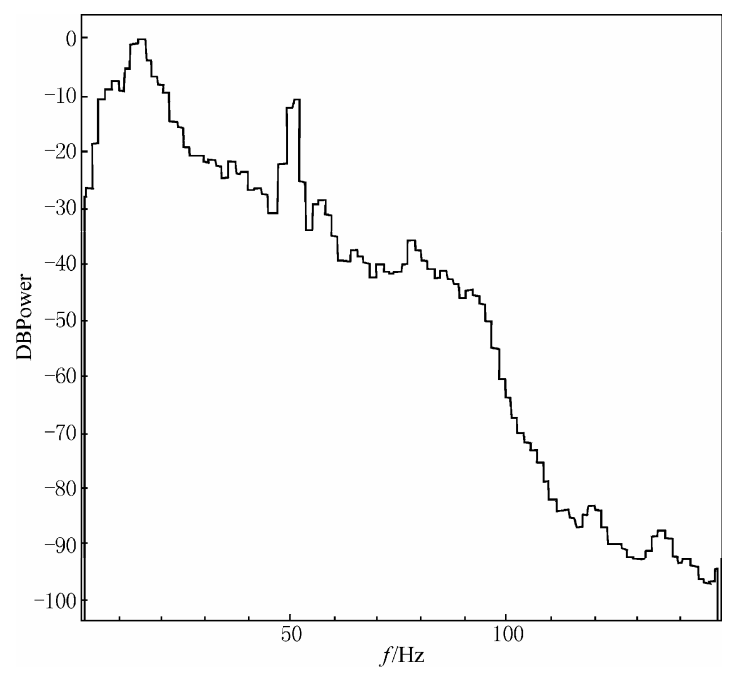

Figure 4 Frequency spectrum of Moho reflection (Shot 6956.5 ) that may be reasonably assumed the $\mathrm{S} / \mathrm{N}$ is greater than one.

\section{Discussion and conclusions}

Deep seismic reflection profiles are difficult to acquire on land using standard oil-industry acquisition parameters especially true over severe topography and complex subsurface structure. Although most of standard oil-industry parameters is usually adopt and available, geologic targets of interest to continental crust reflection not to be limited within sedimentary basin rather than the orogens (Burchfiel et al, 1995; Dirka et al, 1994).

How to obtain adequate data in the areas with high ambient noise levels or signal-penetration impediment by near-surface velocity structures is still a problem encountered periodically during the data acquisition in the Tibetan plateau and its adjacent areas.

The attempt of acquisition with large explosions in US is successful (Jarchow et al, 1990). In this paper, the $200-\mathrm{kg}$ shot gather recorded in west Qinling, northeastern Tibetan plateau with phenomenal signal-to-noise ratios has illustrated the energy of the PmP. The frequencies of Moho up to $60 \mathrm{~Hz}$ suggest that large explosions, despite their low dominant frequencies, may actually have a broader recoverable frequency bandwidth than the standard, less powerful sources. 
Although the observations are only limited to the northeastern Tibetan plateau, which cannot comprise an exhaustive study, they nevertheless suggest that large explosion is applicable and maybe it is a potential way for exploring the areas considered "seismically inaccessible" (e.g. central Tibetan Plateau) when the standard seismic sources fail to produce adequate data.

Logistically, the large-explosive-source profiling is not substantially different from standard industry-explosive-source profiling. The shot depths of $30-50 \mathrm{~m}$ are not prohibitively great and can be easily handled by most drilling crews. However, it is obviously not adequate to make large explosions immediately adjacent to roads, buildings, etc, but the environmental impact of these sources is really less than what is commonly assumed. If large explosions are properly located and adequately tamped, they will rarely disrupt the surface. Indeed, it is difficult to discover the used shot holes after a routine cleanup even when their precise locations are given.

Deep seismic reflection profiles usually have a poor quality because of the adverse effects of variable near-surface conditions, less efficient seismic source coupling, increased environmental noise, and irregular acquisition geometry, among which strong attenuation of seismic wave through the thick cover of flysch sediments deformed during the Late Triassic to Early Jurassic is critical.

Our observations with high signal-to-noise ratios between 16.8 and $18.2 \mathrm{~s}$ TWT suggest that large explosive detonation is applicable and worth attempting in Tibetan Plateau where standard seismic sources often fail to produce adequate data of low crust. The shot gather presented in this article not only show a detailed image of the crust deep to $50 \mathrm{~km}$ beneath west Qinling, but also actually contradicts a firmly entrenched rule that high-frequency seismic energy decreases with increasing shot size.

Acknowledgements This paper was financed by the International Sciences and Technology Cooperation (2006DFA21340), the special funds for the Sciences and Technology Research of Public Welfare Trades (200811021), the key innovation project of sciences and technology of Ministry of Land and Resources (1212010711813), the basic outlay of scientific research work from Ministry of Science and Technology of the
People's Republic of China (J0803), the National Natural Science Foundation of China (40830316 and 40874045), and SINOPPROBE-II.

\section{References}

Brown L D (1987). Lower continental crust: Variations mapped by COCORP deep profiling. Annal Geophy 5: 325-332.

Brown L, Wille D, Zheng L, Devoogd B, Mayer J, Hearn T, Sanford W, Caruso C, Zhu T-F, Nelson D, Potter C, Hauser E, Klemperer S, Kaufman S and Oliver J (1987). COCORP: New perspectives on the deep crust. Geophys $J$ Int 89: 47-54.

Burchfiel B C, Chen Z, Liu Y and Royden L H (1995). Tectonics of the Longmen Shan and adjacent regions, central China. Int Geol Re 37: 661-735.

Dirka P H G M, Wilson C J L, Chen S, Luo Z L and Liu S (1994). Tectonic evolution of the NE margin of the Tibetan Plateau: Evidence from the central Longmen Mountains, Sichuan province, China. Journal of Southeast Asian Earth Sciences 9: 181-192.

Gao R, Ma Y S, Li Q S, Zhu X, Wang H Y, Li P W, Lu Z W and Guan Y (2006a). The lower crustal structure and its relationship of the Songpan block and West Qinling orogen revealed by deep seismic reflection profiling. Geological Bulletin of China 25(12): 1-8 (in Chinese with English abstract).

Gao R, Wang H Y, Ma Y S, Zhu X, Li Q S, Li P W, Kuang Z Y and Lu Z W (2006b). Tectonic relationships between the Zoigê basin of the Song-pan block and the west Qinling orogen at lithosphere scale: Result of deep seismic reflection profiling. Acta Geoscientica Sinica 27(5): 411-418 (in Chinese with English abstract).

Jarchow C M, Goodwin E B and Catchings R D (1990). Are large explosive sources applicable to resource exploration? The Leading Edge 9(1): $12-17$.

Li Q S, Peng S P and Gao R (2004). A review on studies of the Moho discontinuity beneath the Tibetan Plateau. Geological Review 50(6): 598-612 (in Chinese with English abstract)

Mooney W D and Brocher T M (1987). Coincident seismic reflection/refraction studies of the continent lithosphere. Review of Geophysics 25: 723-742.

Wang C Y, Han W B, Wu J P, Lou H and Bai Z M (2003a). Crustal structure beneath the Songpan-Garze orogenic belt. Acta Seismologica Sinica 16(3): $237-250$.

Wang C Y, Wu J P and Lou H (2003b). Crustal P-wave velocity structure in western Sichuan and eastern Tibet. Science in China (Series D) 33(Suppl.): 181-189 (in Chinese with English abstract).

Wang H Y, Gao R, Ma Y S, Zhu X, Li Q S, Kuang Z Y, Li P W and Lu Z W (2007). Basin range coupling and lithosphere structure between the Zoigê and the west Qinling. Chinese J Geophys 50(2): 472-481 (in Chinese with English abstract).

Zhang G W, Guo A L and Yao P A (2004). Western Qinling-Songpan continental tectonic node in Chinese continental tectonic. Earth Science Frontiers 11(3): 23-32 (in Chinese with English abstract).

Zhang X K, Jia S X, Zhao J R, Zhang C K, Yang J, Wang F Y, Zhang J S, Liu B F, Sun G W and Pan S Z (2008). Crustal structures beneath West Qinling East Kunlun orogen and its adjacent area - Results of wide angle seismic reflection and refraction experiment. Chinese J Geophys 51(2): 439-450 (in Chinese with English abstract).

Zhao J R, Li S L, Zhang X K, Yang Z X, Zhang C K, Liu B F, Zhang J S and Pan S Z (2005). Three dimensional Moho geometry beneath the northeast edge of the Qinghai-Tibet Plateau. Chinese J Geophys 48(1): 78-85 (in Chinese with English abstract).

Zhao W J, Nelson K D and Meissner R (1997). Advances of INDEPTH-A deep profiling study in Tibet and the Himalayas. Episodes 20(4): 266-272.

Zhao W J, Nelson K D and Project INDEPTH Team (1993). Deep seismic reflection evidence for continental underthrusting beneath southern Tibet. Nature 366(9): 557-559. 